\title{
The Eleventh All-India Leprosy Workers' Conference and Eighth Conference of the Indian Association of Leprologists
}

No representative conference of leprosy workers in India can fail to be of interest to leprosy workers everywhere. No other country has a comparable leprosy problem. It is estimated that one-sixth of all cases of leprosy in the world are located here, with more patients in a single State than are known in almost any other single nation. It is doubtful whether any other country has such a galaxy of experienced leprosy workers, or a national anti-leprosy programme of comparable magnitude. Quite apart from the cold facts of statistics, the general severity of leprosy, especially in its neurological aspects, the diversity of conditions, the daunting immensity of health problems, all combine to give Indian leprosy workers a representative quality, so that wherever a leprologist may be working, he is likely to find that colleagues in India know his problems only too well, for they encounter them in exaggerated form.

The XIth All India Leprosy Workers' Conference was held in New Delhi from 23 to 25 February, 1969, and followed the usual pattern whereby the Conference of the India Association of Leprologists was held concurrently. This arrangement gives these Indian conferences their special quality. The scientists meet, and burning issues are debated, new developments discussed. At the same time, all types of leprosy worker are present, and actively participate, so that doctor and paramedical worker, surgeon and physiotherapist, occupational therapist and research worker are able to see themselves as a single community, committed to the fight against a great national scourge.

Great advances have been made in the past decade in building up the national anti-leprosy campaign in India. The organization is now widespread, its main features established. The Conference met in a mood of self-examination, seeing the occasion as the opportunity for reappraisal, the sharing of failures as well as successes. Through it there was constantly expressed the need for greater emphasis on social responsibility in leprosy control, and a greater concern for the welfare of the individual patient.

The inaugural Address of the revered late President of India, Dr. Zakir Hussain, established this mood from the start, by recalling the shining example of Mahatma Gandhi in his personal concern for sufferers from leprosy. $\mathrm{He}$ quoted some celebrated words of the Mahatma: "Leprosy work is not merely medical relief; it is transforming the frustration of life into the joy of dedication, and personal ambition into selfless service. If you can transform the life of a patient or change his values of life, you can change the village and the country.",

Dr. Dharmendra, doyen of Indian leprologists, devoted his Presidential Address to socioeconomic problems in leprosy, which are a crucial issue in the anti-leprosy campaign, and unless recognized and faced, may reduce any scientifically planned campaign to frustration and defeat. It is essential both for patients and the general public to recognize that leprosy is a disease like any other disease, and that sufferers from it differ in no way from other patients. The recognition of this fact must lead, on the one hand to a rational attitude towards protection from infection, and on the other to greater kindness, sympathy, and understanding in the treatment of these patients. Dr. Dharmendra traced the causes of dehabilitation of patients, and stressed the importance of skilfully planned health education, early case detection and treatment, including simple physiotherapy, the welfare of patients, and also of rehabilitation --understood as the return of the patient to his 
normal vocation and place in society. The Government of India hoped soon to establish a Rehabilitation Training Centre with these objectives, and hoped also to multiply such centres in the light of the experience gained.

The scientific sessions of the Conference followed the broad issues familiar at all leprosy conferences. Points of special interest may be summarized as follows.

\section{EPIDEMIOLOGY AND CONTROL}

Chemoprophylaxis was the theme of two important papers. Dr. Wardekar, Director of the Gandhi Menorial Leprosy Foundation, reported on a large-scale experiment covering a population of about 40,000 people in an area with a leprosy prevalence of 31 per mille. Over a 4-year period, a reduction of $90 \%$ occurred in leprosy incidence in a population of 11,500 given DJ)S in a dosage for adults of $100 \mathrm{mg}$ daily, as compared with a reduction of $41.9 \%$ in a control group given a placebo. The prophylactic value of I)JS was thus $50 \%$.

Dr. S. K. Noordeen reported on a $5 \frac{1}{2}$-year study in the Chingleput District, of DDS used as a prophylactic among child contacts exposed to infection within their families. Here too, prophylactic IDDS showed an efficacy rate of about $52 \%$. Protection was higher in the younger age-groups and more effective where the index case was bacteriologically positive than when it was bacteriologically negative.

Dr. P. N. Khoshoo gave a wide-ranging survey of epidemiological problems in India. I)r. V. K. Sharma stressed the importance of determining threshold values of leprosy indices at which infection in a community becomes self-sustaining, and discussed the relative usefulness of long-term and short-term studies. Drs. P. S. Rao, A. B. A. Karat and Mrs. Karat discussed patterns of familial aggregation of leprosy in an endemic area. Dr. N. B. Baltha Reddy reported on the pattern of decline in leprosy over 1:3 years in the Polambakkam area. 1)r. M. Christian reported on the course of leprosy in the Laccadive Islands. 1)r. and Mrs. Karat, Dr. P. S. Sunder Rao and Dr. M. A. Furness discussed patterns and prevalence of nerve involvement in leprosy in an endemic area.

\section{CHEMOTHERAPY}

Low dose therapy with DDS was a major issue at this Conference. Drs. A. B. A. Karat, A. Jeevaratnam and P. S. S. Rao in a preliminary communication, reported that with the use of DDS in a dosage of $5 \mathrm{mg}$ daily for 6 days weekly ( 12 patients), and $10 \mathrm{mg}$ daily, 6 days weekly (9 patients), while the morphological index (MI) fell to zero and stayed there the bacterial index (BI) showed either no significant change over a period of one year, or tended to rise. About $33 \%$ of patients developed reactive episodes. On the other hand, I)rs. G. Ramu and K. Ramunujam reported favourably on the use of low dosage 1)DS in 77 lepromatous cases, 100 major tuberculoid cases and over 250 borderline cases, the most gratifying results being obtained with the borderline group.

Three papers presented long-term findings with DDS therapy. I)r. (Miss) C. Vellut reported on the progress over 10 years of 1302 lepromatous cases. Out of 300 patients who took treatment regularly, 10 remained bacterio. logically positive. Among 705 irregular attenders, 158 were still bacteriologically positive. A feature in the series was the appearance of short periods of positive bacteriological findings in the negative phase of treatment, when the original RI has fallen to zero. Such episodes were of short duration and appeared to be without permanent significance. I)rs. A. C. Parikh, R. Ganapati and N. I). Katdare also reported on the progress over 10 years of 123 lepromatous eases. While the progress of the majority was good, there remained a small group who re. mained stubbornly bacteriologically positive, and incidentally, appeared never to suffer from reactive episodes. Nine patients became negative with what was in fact a low dosage of DDS'. J)r. C. S. G. Sharma also spoke on chemotherapy on the mass scale in a field unit over a 14-year period.

Dr. J). N. G. Nambidiripad spoke a cautionary word on the use of corticosteroids, and D. Ojiha, C. Singh and Y. N. Upadhyaya reported encouraging results in the use of the herb Acacia catcchu (Willd). 


\section{PATHOLOGY AND IMMUNITY}

Drs. K. V. Desikan and C. K. Job presented a comprehensive pathological study of visceral lesions in leprosy. Interesting points included the presence of tuberculoid lesions in liver and testes, the presence of pyelitis in all lepromatous cases examined at autopsy, and the freedom from involvement of mesenteric and mediastinal glands. Prof. S. Ghosh and Dr. S. K. Chaudhury discussed concomitant infection with leprosy and tuberculosis. Dr. C. K. Job demonstrated histopathological appearances in tuberculin and lepromin reactions, and Dr. D. K. Dastur, in a, paper on nerve degeneration and regeneration in leprosy, referred to the sparing of thick axons even in severely degenerating nerves, the parallel processes of degeneration and regeneration and the involvement of intramuscular nerves in the disease process.

A highlight of the session, and indeed of the whole Conference, was the presentation by Dr. A. B. A. Karat of experiments in the growth of Myco. leprae in the footpads of Swiss white mice (Rockefeller strain) without constant thermoregulation, success having been obtained in 44 out of 46 experiments. This is a remarkable achievement.

\section{CLINICAL MANIFESTATIONS}

An interesting paper was presented by Drs. K. Ramanujam and G. Ramu on 100 cases of histoid lepromatous leprosy, which while displaying many features similar to those described by Wade, also showed some distinctive features. The generally favourable prognosis with DDS therapy, and some association with a borderline pathology in certain cases were noted. Prof. S. Ghosh and Dr. S. K. Kundu presented a study of 4.319 cases of maculo-anaesthetic leprosy. Dr. A. B. A. Karat, in a preliminary communication, found that patients with megaloblastosis in general have reduced vitamin-Bl2 and folate levels in the serum, with lower levels of folate in the bacillated forms of the disease. Drs. A. C. Parikh, R. Ganapati and N. D. Katdare discussed diagonostic problems in relation to dermatological conditions. Drs. S. Karat, A. B. A. Karat and P. Pitchandy presented electro-myographic studies in changes of conduction velocity in the ulnar nerve in lepromatous leprosy. Dr. and Mrs. Karat with M. A. Furness also described a simple electrodiagnostic test to apply in cases of facial palsy to help determine prognosis.

\section{RECONSTRUCTIVE SURGERY AND PHYSIOTHERAPY}

$V$ arious aspects of the expanding role of surgery in correcting the disabilities and sequelae of leprosy were presented by specialists in several fields. Dr. V. I. Buch spoke on recent trends in the cosmetic reconstruction of the face, referring particularly to the naso-labial face-lift, both for cosmetic purposes and for lining the nasal cavity, and chemical face peeling to remove circumoral wrinkles. Drs. Mrs. S. Karat, A. B. A. Karat, U. Jacobson and C. Johnson analysed the pattern of nasal deformity in 1800 lepromatous leprosy patients and described 5 typical patterns. Dr. H. Srinivarsan described a new technique for correcting deformity of the thumb. Dr. R. H. Thangaraj described a modified technique for tibialis posterior tendon transfer for drop foot. I). M. P. Achutha Menon stressed the role of the intrinsic muscles of the foot as a predisposing factor in plantar ulceration. Mr. N. Palani discussed the detailed pre- and post-operative physiotherapeutic management of drop foot, and M.r. S. L. Kolumban dealt with the role of static and dynamic splinting in straightening contracted proximal interphalangeal joints. Dr. F. P. Fritschi and Mr. P. Antony also offered valuable contributions to this session.

The remaining sessions were described as "working sessions" and were of a more domestic character, concerned primarily with a fresh look at the National Leprosy Control Programme. This Programme, planned and developed in India over the past 15 years, is well worth study by leprologists everywhere. Concentration on case detection and case holding, the mass treatment of infective cases on a domiciliary workers, health education, and co-operation by voluntary agencies, are all features of it.

A vast amount of experience is now ac- 
cumulating. The achievements of the Programme have been very great, particularly in the light of the enormous difficulties with which it had to contend from the start. It is now planning to identify areas of special success or weakness in methodology and operation. One whole session was devoted to this. Dr. P. N. Khoshoo, Assistant Director-General (Leprosy), spoke on "A fresh look at the leprosy control programme", emphasizing its basic principles, its successes, and the further developments still required. Special reference was made to the need for research, with the Government of India now undertaking its own study of BCG vaccination in leprosy prophylaxis. Dr. P. Kapoor described the progress of the leprosy control programme in Maharashtra, and suggested modifications in methodology. Dr. V. Ekambaram spoke similarly in relation to Tamil Nady, the most heavily infected State in India, stressing the importance of health education. Messrs. M. Aravindam and S. Adivaraham spoke on the assessment of Survey, Education, and Treatment Centres, which form a prominent feature of the programme. Mr. V. Vedradi emphasized the importance of school surveys. Dr. K. Suresh described the large-scale control work of the Danish Save the Children Organization at Pogiri, and the clear signs of control now developing. Mr. N. S. Sadagopan presented a valuable discussion on the place of the individual patient in the mass leprosy campaign with special reference to Polambakkam leprosy centre.

A whole session was devoted to health education in relation to leprosy. At various centres much thought has been given to this subject, and methods of operation worked out which are as interesting as they are valuable. Dr. R. V. Wardekar spoke of the work of the Gandhi Memorial Leprosy Foundation in this sphere. A very comprehensive programme directed to urban areas is operating, and is worthy of careful study; the need to use a wide range of media and methods was stressed. 1)r. T. N. N. Bhattithiripad described the creation and functions of local Leprosy Welfare Committees attached to local leprosy centres; these he had found to be very valuable means of changing public opinion and evoking community interest in leprosy control.

Another session was devoted to taking a fresh look at rehabilitation, another subject on which a lot of thinking is going on in India. Sri Antony Sami described Leprosy Rehabilitation Training Centres, expanding Dr. Dharmendra's remarks in his Presidential Address. Mr. G. K. Chenkiah made a plea for rehabilitation homes for women. Mr. A. G. Rameshchandra referred to reconstructive surgery as a preparation for rehabilitation. Mr. L. Wollstein described various types of prosthesis and splint, and discussed their value. Mrs. Soderberg illustrated the usefulness of plaster treatment for plantar ulcers. Miss Thistlethwaite advocated preventive rehabilitation through simple but well-documented physiotherapy at local treatment clinics. Dr. A. J. Selvapandian spoke on the socio-economic evaluation of leprosy patients with plantar ulcer.

The final working session of the Conference dealt with the role of voluntary agencies in leprosy control. In the past, voluntary agencies have had a distinguished record in India in caring for the individual patient, developing reconstructive surgery, physiotherapy, and various aspects of rehabilitation. Prof. T. N. Jagadian, Organizing Secretary of the Hind Kusht Nivaran Sangh emphasized the important continuing role for voluntary agencies in India, setting the highest standards of personal care, finding areas of unmet human need, and developing a well-informed active programme around it. Beneficence and an inherent capacity to promote understanding and evoke cooperation are the hallmark of the effective voluntary agency. Di. V. P. Das took up the same theme, emphasizing the need for voluntary agencies to be selective in the work they try to do, regarding their work as supplementing Government effort. Dr. Yudhvir Singh described the work of voluntary agencies in the Delhi area. Mr. C. S. Dalmia described the work of the Santal Paharia Sevamandal. In the discussion following these papers the important con- 
tribution which voluntary agencies can bring to the national anti-leprosy programme was repeatedly brought out, co-ordinated with, and supplementing, the Government programme.

Throughout the Conference, discussion was brisk and many points of interest arose. The deliberations of the Conference were summed up at its close by Dr. V. P. Das, President of the Indian Association of Leprologists.

A small but attractively presented exhibition, "From Darkness to Light", drew the interest of many delegates.

T. F. DAVEY. 